\title{
Through 40,000 years of human presence in Southern Europe: the Italian case study
}

\author{
Serena Aneli ${ }^{1}$ (1) $\cdot$ Matteo Caldon $^{1} \cdot$ Tina Saupe $^{2} \cdot$ Francesco Montinaro $^{2,3} \cdot$ Luca Pagani $^{1,2}$
}

Received: 8 June 2021 / Accepted: 29 July 2021 / Published online: 19 August 2021

(c) The Author(s) 2021

\begin{abstract}
The Italian Peninsula, a natural pier across the Mediterranean Sea, witnessed intricate population events since the very beginning of the human occupation in Europe. In the last few years, an increasing number of modern and ancient genomes from the area have been published by the international research community. This genomic perspective started unveiling the relevance of Italy to understand the post-Last Glacial Maximum (LGM) re-peopling of Europe, the earlier phase of the Neolithic westward migrations, and its linking role between Eastern and Western Mediterranean areas after the Iron Age. However, many open questions are still waiting for more data to be addressed in full. With this review, we summarize the current knowledge emerging from the available ancient Italian individuals and, by re-analysing them all at once, we try to shed light on the avenues future research in the area should cover. In particular, open questions concern (1) the fate of preVillabruna Europeans and to what extent their genomic components were absorbed by the post-LGM hunter-gatherers; (2) the role of Sicily and Sardinia before LGM; (3) to what degree the documented genetic structure within the Early Neolithic settlers can be described as two separate migrations; (4) what are the population events behind the marked presence of an Iranian Neolithic-like component in Bronze Age and Iron Age Italian and Southern European samples.
\end{abstract}

\section{Introduction}

An increasingly detailed portrait of ancient Europe has been emerging in the last few years thanks to the joint analyses of archaeological findings, and the pattern of modern and ancient genetic variations elucidating past cultural transitions. The coarse edges of the European mosaic have been traced by three major contributions arriving in different periods and from different homelands: the first hunter-gatherers on the European ground, the Neolithic farmers from Anatolia, and the Bronze Age herders from the Steppe (Lazaridis et al. 2014; Haak et al. 2015). However, even though we have certainly found the tesserae composing the main figure, we still lack some fine details and we are far from putting together the blue sky pieces.

Serena Aneli

serena.aneli@unipd.it

1 Department of Biology, University of Padova, Via Ugo Bassi, 58/B, 35131 Padova, Italy

2 Estonian Biocentre, Institute of Genomics, University of Tartu, Riia 23b, 51010 Tartu, Estonia

3 Department of Biology-Genetics, University of Bari, Via Edoardo Orabona 4, 70125 Bari, Italy
In this context, due to its position at the centre of the Mediterranean Basin, Italy is an ideal country to unearth the genetic footprints of at least some of the past demographic events in Southern Europe, thus offering the opportunity to add new pieces to the puzzle until clearer pictures emerge from our past. Indeed, its geographical features and the mild climate have been attracting people both near and far during the main stages of the peopling of the continent (Pais 1988).

Since Upper Palaeolithic, around 45,000 years ago (kya), modern humans have lived there (Benazzi et al. 2011, 2014), and during the LGM (18-20kya) Italy and the other Southern Mediterranean areas were used as refugia from the North (Stewart and Stringer 2012). The Italian Peninsula also played a major role in spreading the farming lifestyle, through at least two diffusion routes: one started from Apulia, where the most ancient findings associated with farming were discovered and following the Eastern coast reached the North, while the other started from East Sicily and travelled up along the Tyrrhenian coast (Pessina and Tiné 2008; Boattini et al. 2013).

During the Neolithic and for thousands of years later, the Mediterranean Sea itself contributed to shortening the distances and making Italy one of the gateways to the European continent: first acting for millennia as a barrier separating 
the African and the European continents, and then turned into a bridge as the first Bronze Age seafarers started to travel in open water (Broodbank 2006). Another hallmark of the Italian landscape contributed significantly to the cultural ferment of such times: the Alps. Indeed, they were so rich in copper that some Copper Age cultures arose in Italy, at Remedello and Rinaldone in the North and Gaudo in the South (Mallory et al. 1997). The diffusion of these metalworkers is evident in Ötzi, the South-Tyrolean Iceman. He carried a copper axe of the Remedello type, which was produced in Northern Italy using the ores of Tuscany (Keller et al. 2012; Artioli et al. 2017). During the Bronze Age, at least two ancestral sources moved through Italy, the Stepperelated component and an Iranian farmer-related component, whose amount steadily increased during the Iron Age period (Marcus et al. 2020; Fernandes et al. 2020). Moreover, the distribution of these components is still visible in the genomes of modern Italians (Sarno et al. 2017; Raveane et al. 2019).

Later on, the rise of the Roman civilization and its tight network of trade, political, religious, and cultural connections over one of the largest empires in the ancient world contributed to shuffle and mingle different genetic components across the Mediterranean, Continental Europe and Northern Africa (Antonio et al. 2019). With all this back and forth, the population inhabiting the country have been accumulating the genetic traces of these ancient wanderings, thus exhibiting the largest genetic diversity in Europe (Capocasa et al. 2014; Fiorito et al. 2016; Sazzini et al. 2016; Anagnostou et al. 2017; Raveane et al. 2019).

In the last few years, the scientific community has collected a huge amount of information from human remains and material culture discovered worldwide and through a wide range of time. Such data represent an extraordinary asset to solve the outstanding questions concerning the demographic events experienced by ancient populations. While a thorough assessment of all sources of scientific evidence would be the preferred approach to tackle such a broad research question, here we will only focus on genetic evidence as the primary source of information.

In this review, we collected and analysed all the genetic data of ancient Eurasian individuals which have been generated so far, focusing on their variable sites and clustering ancient samples by the culture of major genetic components with no assumptions on their belonging to discrete population units, together with a reference of modern populations from the same areas (Fig. 1, Supplementary Figs. 1, 2 and Supplementary Table 1). In particular, more than three hundred of them come from Italy, ranging from the Late Palaeolithic to Medieval times, thus offering the exciting opportunity to glimpse some broader pictures from our past. For this reason, taking Italy as a case study we recapitulate the main steps of the peopling of Europe, highlighting outstanding questions that may hopefully be addressed in the coming years.

\section{From the first peopling of Europe to the Villabruna hunter-gatherers}

The first humans inhabiting Italy were archaic humans: remains of putative Homo erectus (Peretto 2006), Homo heidelbergensis/Ceprano and Neanderthal were found throughout Italy and date back from as early as 1 million years ago to 40kya (Manzi et al. 2001; Bruner and Manzi 2006; Lari et al. 2015). The Homo sapiens occupation of the Italian Peninsula started quite early and intriguingly overlaps the Neanderthal one. Notably, the Grotta del Cavallo (Apulia, Peninsular Italy) (Benazzi et al. 2011) provides one of the earliest evidences of sapiens in Europe and it is associated with a cultural package, the Uluzzian technology, which may show influences from both human groups. Ancient genomic evidence (Fu et al. 2016) showed that the Italian genetic substrate was connected with that of continental Europe, with remains found in archaeological sites like Paglicci and Ostuni (both located in Apulia and dating back to 33kya and 28kya, respectively) showing genetic affinities with the so-called "Vestonice cluster". This group of individuals spanned all the way from the Russian Steppe to Central Europe until the beginning of the last Ice Age (25-20kya) and falls outside of the human diversity described by modern human samples [Supplementary Fig. 3, in some cases their high genetic diversity when compared to present-day human populations is reflected in the Principal Component Analysis (PCA) by a shift towards the center of the coordinate system (Fu et al. 2016)]. These Italian sites are all associated with Gravettian material culture (33-21kya), which is argued to have provided a substrate for the in-situ development of Early Epigravettian, the landmark of the fossil record dating to the Last Glacial Maximum (LGM) and potentially pointing to the role of Central and Southern Italy as glacial refugia (Stewart and Stringer 2012).

During the LGM, at around 20-19kya, Italy was by and large disconnected from the rest of continental Europe by the Alpine Icecap (Peresani et al. 2020). At the same time, it was accessible from the Balkan Peninsula through land bridges spanning the Adriatic Sea. These connections provided crucial for the establishment of trade and cultural exchanges with groups from the Balkans and the Black Sea region (Peresani et al. 2020), which ultimately resulted in genetic exchanges. The most notable evidence of such a gene flow is represented by the so-called Villabruna replacement, which is represented by the arrival of genetic components with a higher affinity to contemporary Near Eastern groups and which formed the basis for the post-Ice Age European genetic landscape (Fu et al. 2016). The earliest evidence of such a massive replacement is represented by the Tagliente 2 

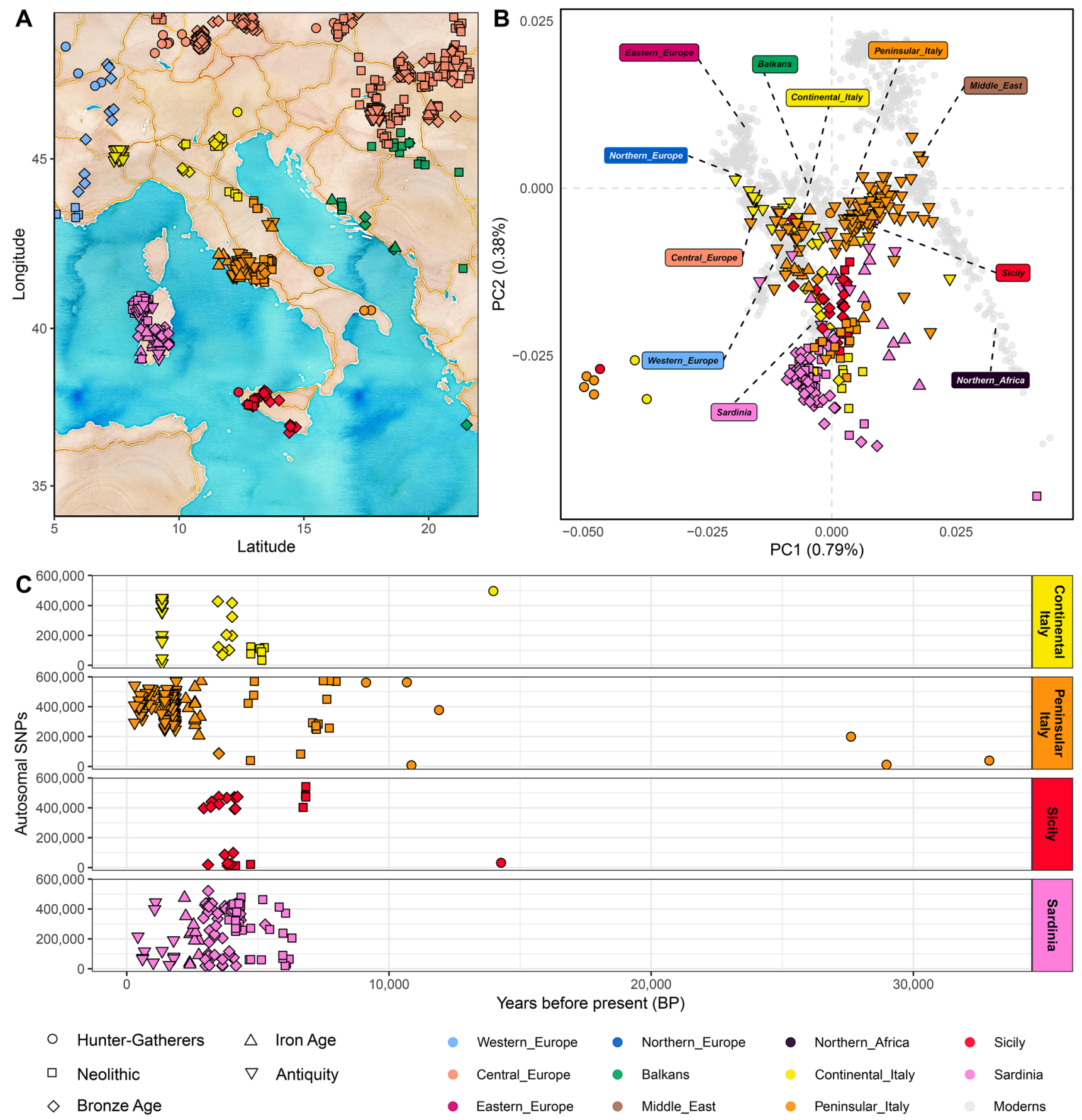

Fig. 1 Ancient Italian individuals discussed in this review. A Geographical location of ancient individuals from Italy and surrounding areas. The Italian ancient individuals are divided into four main categories: Continental Italy (yellow), Peninsular Italy (orange), Sicily (red), and Sardinia (pink); B Principal component analysis (PCA)

sample from Riparo Tagliente (near Verona, Northern Italy) dated to $17 \mathrm{kya}$ and for which a whole-genome shotgun sequence is available (Bortolini et al. 2021). Although based on mtDNA evidence alone, earlier traces of Villabruna-like genome may be seen in some Paglicci samples dated to projecting the ancient Italian individuals onto the genetic variation of present-day individuals (in grey). C Chronological distribution $(x$-axis) and the number of autosomal SNPs of the ancient Italian individuals ( $y$-axis, proxied by the number of available SNPs from the standard $1240 \mathrm{~K}+\mathrm{HO}$ (Human Origin array) SNP set)

$19 \mathrm{kya}$, at the very end of LGM (Posth et al. 2016). Villabruna and Tagliente2 (in yellow, Fig. 2A, B) fall at the centre of the other post-Villabruna HG samples, from which they differentiate towards Italy and the rest of Europe (Fig. 2B), showing the pivotal role of these early Italian samples in 


\section{Post-Villabruna hunter-gatherers}

A

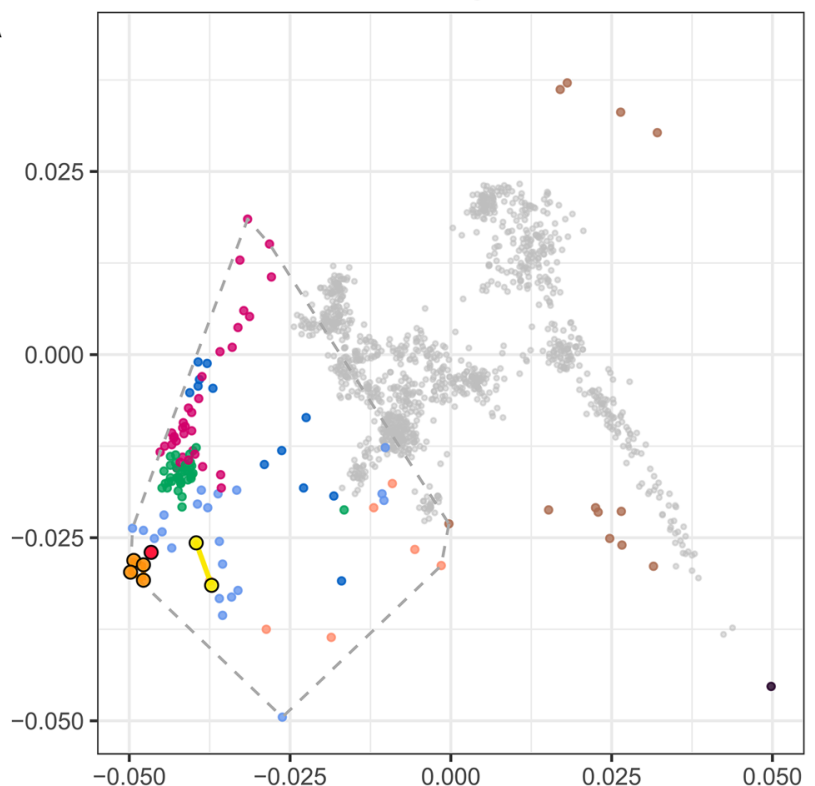

Neolithic

C

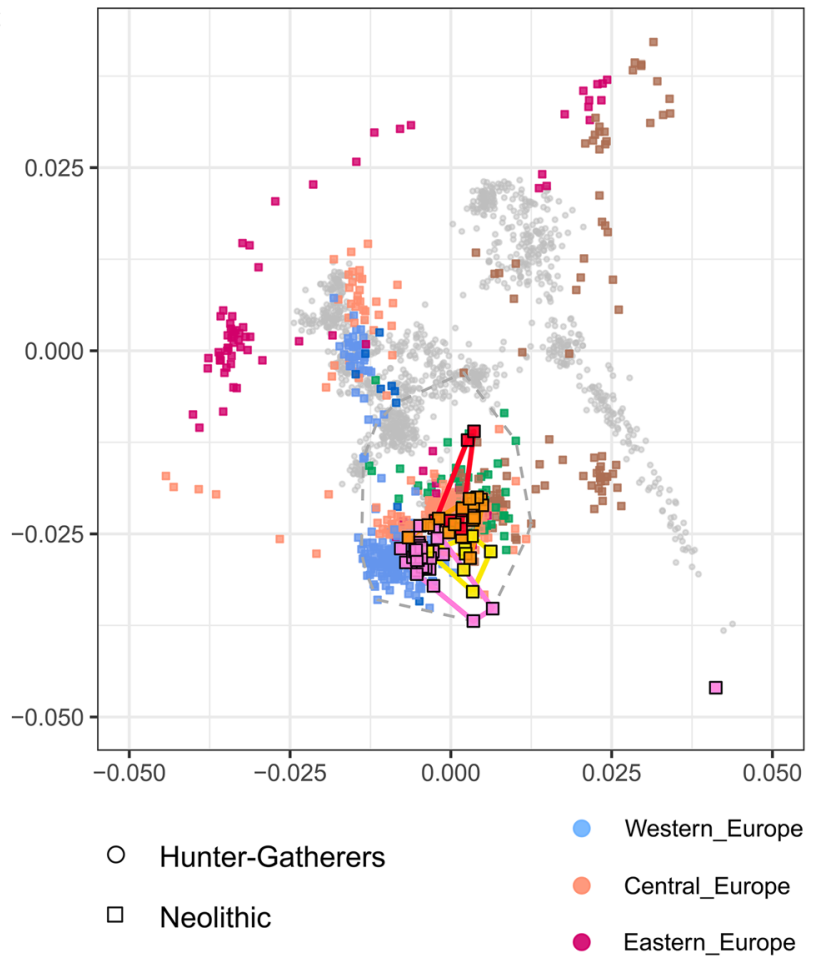

Fig. 2 PCA and outgroup $f_{3}$ multidimensional scaling (MDS) for samples dated back to Paleo-Mesolithic (hunter-gatherers) and Neolithic periods (A-D, respectively). Samples were divided into four groups according to their chronological and cultural affiliation and projected onto the genetic variation of modern West Eurasians (left column, panels $\mathbf{A}, \mathbf{C}$ ) along with a number of modern reference sam-
B

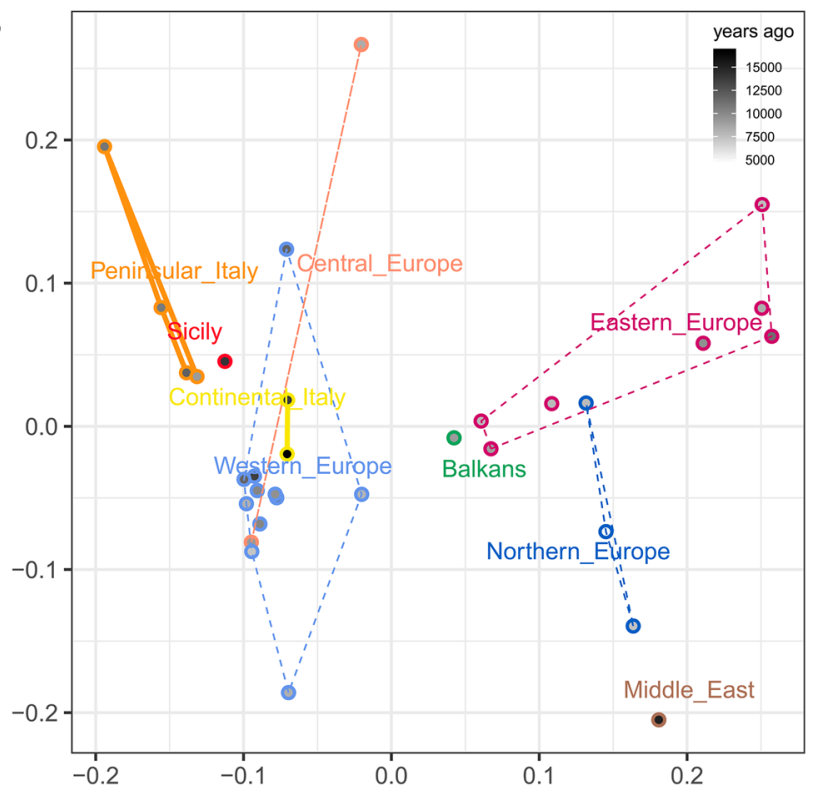

D

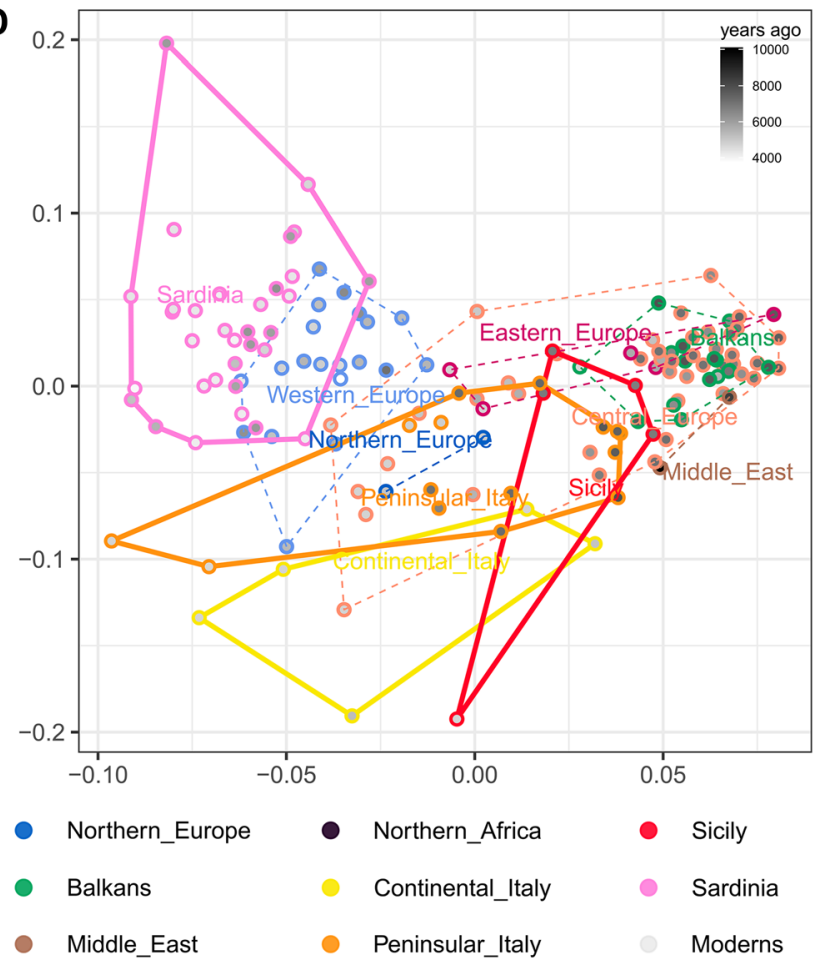

ples from neighbouring regions. Samples within the dashed grey polygons were also used to construct a pairwise matrix of outgroup $f_{3}$ distances in the form of $f_{3}$ (Mbuti; $\mathrm{X}, \mathrm{Y}$ ) on which an MDS was performed, hence providing a complementary visualization to the PCA. The chronological dating, based on mean date BP (before present), was used to color-code the samples (right column, panels $\mathbf{B}, \mathbf{D}$ ) 
explaining the subsequent Western Hunter Gatherers (WHG) genetic diversity. The emerging scenario hence seems to place Italy as the first step of the re-colonization of post-Ice Age Europe by settlers coming from the East potentially as early as 19 or 20kya. This population movement introduced in Southern Europe, through demic diffusion, the Epigravettian cultural package (Bortolini et al. 2021) and may have initiated other cultural transitions given the presence of a similar genetic component found in the genome of the individual ElMiron, who lived 18.5kya in Spain and that was associated to Magdalenian culture (Fu et al. 2016). A similar, parallel movement from the Balkan/Black Sea region towards the North, with genetic contributions from Central/ East Eurasia, may explain the origin of Eastern Hunter Gatherers (EHG), who indeed seem to align along an orthogonal axis from the one described by the WHG (Fig. 2B), although this is beyond the scope of the current review. While LGM can be seen as the major cause for the disappearance of preVillabruna people in Central and Northern Europe, it is still poorly understood what may have caused the disappearance of the genetic components related to the Vestonice cluster in later individuals in Italy. One scenario may involve the Epigravettian package brought by the Villabruna people as the key for their ultimate success, although more Southern Italian samples from 20 to 15 kya may show a less dramatic scenario, perhaps providing a clue to interpreting the socalled WHG component in light of pre and post Villabruna admixtures (Sazzini et al. 2020). Another outstanding question is the role of the major Italian islands (Sicily and Sardinia) during the pre and post-Villabruna periods. We know from Grotta d'Oriente (Sicily) that WHG arrived there at least as early as 14kya (Catalano et al. 2020). However, the presence of Vestonice-like individuals in Sicily and of Vestonice or Villabruna-like individuals in Sardinia is an as-yet unexplored chapter.

\section{Neolithic and copper age}

The term "Neolithic Revolution" refers to the five millennia-long process (approximately between 12,000 and 7000 ya) involving dramatic changes in the behavior, culture, and ecology of human populations, culminating in the domestication of plants and animals, and the almost ubiquitous adoption of pottery (Fowler et al. 2015). The Western Eurasian origin of these changes has been geographically placed in the Fertile Crescent, an area including the Southern part of Anatolia, modern-day Western Iran, Iraq, Syria, Lebanon, Israel, Palestine, Jordan, and Egypt. After their emergence, techniques and artifacts associated with Neolithic culture spread very fast, reaching Iberia already by 7450 ya (Hofmanová et al. 2016). The how and when of its expansion in Europe has been a very debated subject till the last decades, in which a spectrum of purely demic/purely cultural models was advocated by many scholars, including geneticists (Ammerman and Cavalli-Sforza 1984). Although many genetic studies, including the pioneering ones started by Cavalli Sforza and colleagues, tentatively attempted to address the Neolithic Revolution dynamics (Ammerman and Cavalli-Sforza 1984; Cavalli-Sforza 2001), the ultimate verdict was reached only recently, when the analysis of genetic material extracted from human remains confirmed a mostly demic diffusion, with a complex genetic interaction with local hunter gatherers (Skoglund et al. 2012; Gamba et al. 2014; Lazaridis et al. 2014; Olalde et al. 2015). It is globally accepted that this demic diffusion followed both a Mediterranean route (following the Mediterranean coasts, including Italy) and a continental route (Balkan route reaching Central and Western Europe through the Danubian valley), with the terminal fringes of this migration admixing again. Furthermore, quantitative and systematic analysis of the archaeological records found support for an expansion characterised by "boom and bust" (Shennan et al. 2013), in which expansions were followed by stasis. Archaeological records, such as the Impressed/Cardial Ware (Southern Europe along the Mediterranean shores) and Linear ceramic cultures (LBK, Central Europe) named after the peculiar practice of pottery ornamentations, suggest the existence of at least two different routes of colonisation of Europe. Although the global outlines of the European Neolithization are now known, many specific and local aspects are missing. As an example, despite their marked difference in Archaeology, it is not clear how these groups from the two waves were differentiated.

Although in two expanding populations from the same source or geographic area, the amount of genetic drift would be very low, investigations on modern samples have shown that the state of art genetic analysis would be able to pinpoint even the subtlest difference among different groups (Pankratov et al. 2020).

However, clear genetic signals of this double expansion have not been found so far (Haak et al. 2015). This could possibly depend on the small sample size of the available ancient populations, combined with the relatively low quality of genotype and sequence data, not having enough power to recover the subtle differences between the two Neolithic founder populations. However, with the increase of ancient samples examined, subtle differences between Central-West and Central-East Europe started to emerge, with samples from Western and Eastern Europe forming two distinct clusters in the PCA (Fig. 2C) (Olalde et al. 2015; Rivollat et al. 2020; Marcus et al. 2020; Saupe et al. 2021). F4 statistics and related method (qpAdm) showed that this separation is possibly due to different amounts of ancestry related to WHG. It may be possible that the populations spreading through Central and Mediterranean routes mixed differently with residing hunter-gatherer populations, with the former witnessing a higher number of admixture events, in line with 
some archaeological evidence suggesting a sparser mesolithic hunter-gatherer population in Southern Italy, although new archaeological surveys are needed (Mussi 2006; Martini 2019). On the other hand, the genetic drift and founder effect acting independently in the two groups might have given origin to differences in allele frequencies and haplotype patterns, which have not been uncovered so far. Notably, when focusing on Italy, most Italian Neolithic samples are closely related to the Central European cluster (Fig. 2C, D, salmon color), with the only exception of Peninsular Chalcolithic (6632-4630 ya) and Neolithic Sardinian (6299-3896 ya) individuals (Fig. 2D, pink and orange circles) which are more related to the Mediterranean cluster. This peculiar pattern is potentially mirrored by Y-chromosome analyses (Rohrlach et al. 2021), an adequate coverage of which is beyond the scope of the current review.

Nevertheless, many aspects of the Neolithic diffusion West of the Adriatic have not yet been characterised. The lack of Neolithic samples from Peninsular Southern Italy, the first Italian area to be affected by the Neolithic wave, makes it impossible to understand the most probable genetic sources. Another open question concerns whether multiple streams reached Italy, as cultural differences in Sicilian and Adriatic Italy (e.g., Apulia) tentatively suggest (Pessina and Tiné 2008).

\section{Bronze age}

European populations were just swept up by the Neolithic wave that another time of great demographic and cultural turmoil was approaching. The Eurasian Bronze Age (between around 5000-3000 ya) was a period of major cultural changes, indeed, with the introduction of new metalworking techniques and breakthrough innovations, such as the wheel, the chariot and the ox-drawn plough, the rising of the first cities and the intensification of commercial networks whose routes for selling metal goods connected people from far and wide (Harding and Fokkens 2013; Allentoft et al. 2015). However, whether these changes were gradually diffused by the movement of people or the spreading of ideas remained disputed for a while.

The initial answers to this debate came from the PonticCaspian steppes, where the Yamnaya, a nomadic culture based on sheep and cattle herding, emerged at least 5000 ya. The kurgan, a round tumulus or barrow built upon a grave, was one of their distinctive elements, representing also an important step in the direction of modern civilization because, for the first time, single rather than collective graves were introduced (Manco 2016). Gradually, elements of their culture began to be found in Europe and Central Asia, up to the foothills of the Altai Mountains. From the genetic point of view, the Yamnaya population was a mixture of different ancestries: EHG and CHG-related ancestry, the latter possibly deriving from the Maykop culture (Jones et al. 2015), as well as traces of the first farmers of Northern Iran, which together are usually referred as "Steppe-related ancestry". Steppe-related ancestry appeared in Europe with the Corded Ware population as early as 4750 ya (Allentoft et al. 2015; Haak et al. 2015). Along with part of their DNA, the Corded Ware shared with the Yamnaya many other traits, such as the large burial mounds, the intensive use of horse and herding, a male-centred culture and the finely executed copper axes (Haak et al. 2015). Another European society shared some cultural as well as genetic legacy from the Yamnaya - the Bell Beakers-but, in contrast to the Corded Ware (Saag et al. 2017; Mittnik et al. 2018), they exhibited a high genetic heterogeneity: while Iberian Bell Beakers were genetically indistinguishable from the people who lived there earlier (Olalde et al. 2018), Bell Beakers from Central Europe showed a considerable amount of their ancestry deriving from the Steppe populations. With the Steppe-related ancestry, the third ancestral component of the European genetic make-up and the one contributing the most to it had been found (Lazaridis et al. 2014). At that point, the European genetic puzzle was apparently completed with the Corded Ware and Bell Beaker migrations as the major spreaders of the high level of Steppe-related ancestry we see in modern-day Europeans, at least in Northern and Central Europe (Raveane et al. 2019).

Southeastern Europe was the first European region to receive the Steppe-related ancestry, with sporadic individuals showing this component in Bulgaria as early as 6700-6500 ya (Mathieson et al. 2018), to the point that during the Bronze Age almost everyone there harboured around $30 \%$ of Steppe-related ancestry. Also, Sicily received this ancestry after $\sim 4150$ ya, while Sardinia had to wait until the Iron Age (Sarno et al. 2017; Fernandes et al. 2020). More specifically, the timing of the Steppe-related ancestry arrival in Italy was a central topic of a recent study, examining human remains from Northeastern and Central Italy dated to the Chalcolithic and Bronze Age (Saupe et al. 2021). As a confirmation of other Central European studies (Olalde et al. 2018), they found a gradual increase in such ancestry over time, with the first appearance in Early Bronze Age Italians (Italian Bell Beaker 4000 ya (Olalde et al. 2018), Italian Remedello 3900 ya (Allentoft et al. 2015), and Grottina dei Covoloni del Broion dated 3800 (Saupe et al. 2021). Moreover, Saupe and colleagues retraced the arrival of the Steppe-related ancestry in Northeastern Italy as early as 3900 ya and in Central Italy as early as 3,550 ya.

The Bronze Age Aegean civilizations, mainly represented by Minoans and Mycenaeans, also harboured up to a quarter of their ancestry ultimately connected with ancient populations from Caucasus and Iran. Nonetheless, only the Mycenaean individuals also showed the EHG-related component (Lazaridis et al. 2017). For this reason, at least in 
the Minoans, the three-way split ancestral contribution is not completely fulfilled and raises other issues about who brought the Caucasus/Iran-related component into Europe.

The widespread commercial networks, facilitated by the introduction of chariots and the technological advances in seafaring, allowed long-distance mobility never seen before (Abulafia 2011). In this context, the geographical position of Italy at the centre of the Mediterranean Sea could help reconcile the cryptic source of the Caucasus-related ancestry, and several aDNA studies based on Italian archaeological sites came out in the last few years also trying to address this issue (Antonio et al. 2019; Marcus et al. 2020; Fernandes et al. 2020). The work from Antonio and colleagues examined the genetic transitions experienced by Central Italians which, during the Iron Age, would have given origin to the founders of the Roman civilization (Antonio et al. 2019). While they detected the suggestive presence of a small amount of the Caucasus/Iran-related component as early as the Neolithic period, they observed an increase of that component during the Bronze and Iron Age (between 4800 and 2850 ya), possibly due to increased trade-driven mobility.

The same long-distance mobility with the resultant genetic transitions has been highlighted by the other recent studies focusing on the islands of the Western Mediterranean Sea: the Balearic Islands, Sardinia, and Sicily (Marcus et al. 2020; Fernandes et al. 2020). Both Sardinia and Sicily received the cultural influxes of the Bell Beaker complex after 4450 ya (Ugas 2006; Harding and Fokkens 2013; Fernandes et al. 2020), but similarly to the Iberian situation, that happened without bringing along the Steppe-related ancestry: indeed, Beaker-associated individuals in both islands do not harbour Steppe ancestry (Olalde et al. 2018; Fernandes et al. 2020). The Steppe ancestry started appearing in Sicily around 4150 ya, during the Early Bronze Age, as demonstrated by qpAdm modelling on autosomal genetic variation with two notable outliers carrying up to $20 \%$ and $40 \%$ of this genetic component (Sicily_EBA8561 and Sicily_EBA11443, (Fernandes et al. 2020). Starting from the Middle Bronze Age (3750-3450 ya), Sicilian samples show a considerable shift in the PCA towards Minoans and Mycenaeans (Fig. 3A, Minoans and Mycenaeans are grouped in the Balkan area in green) and can be modelled with the Iranian-related component in a percentage around 15\% (Fernandes et al. 2020). This data opens up the fascinating possibility that this mysterious ancestry must have reached Southern Italy before the occupation of the southern coastal areas of Italy (Magna Graecia). Conversely, ancient Sardinians showed a higher degree of genetic continuity from the Neolithic to the Bronze Age, with almost all individuals showing similar proportions of Anatolian Neolithic and WHG ancestries. This peculiar situation strongly differs from many other European regions, where the Bronze Age brought huge demographic and cultural turmoil and suggests genetic isolation from mainland populations (Marcus et al. 2020). Two interesting exceptions within the Sardinian individuals regard two outliers showing the former a huge proportion of Northern African ancestry (around 77\%) and the latter carrying Eastern Mediterranean or Steppe-related components (Fernandes et al. 2020). During the Middle Bronze Age, about 3550 ya, archaeological evidence showed the appearance of the Nuragic culture, named after the Sardinian most characteristic stone towers called nuraghi. Despite the absence of the Iranian-related ancestry until the Iron Age, this period was characterized by the intensification of trades and cultural exchanges bridging together the lands facing the Mediterranean, as testified, for instance, by the arrival of copper goods from Cyprus in the Late Bronze Age Sardinia (Sabatini and Lo Schiavo 2020) and the presence on the island of Mycenaean, Levantine and Cypriot traders. Nevertheless, evidence of gene flows altering the genetic continuity did not appear until after the Nuragic period (Marcus et al. 2020).

\section{Iron age}

The Iron Age, the latest protohistoric period before the beginning of Antiquity History and Historiography, in Italy and Western Europe started between the 2nd and the 1st millennium BCE (Before Common Era) and ended with the Roman conquest (Peroni 1989; Cunliffe 2008). This period was characterised by the development of new metallurgic techniques and the consequent mass appearance of iron artifacts in archaeological sites (Bietti Sestieri 2018). It was also a period of demographic growth, social, and political stratification as well as the intensification of trade networks. Multiple Iron Age populations characterized by different languages and cultures lived in Italy but, genetically speaking, they started to approximate the modern Italians (Aneli et al. 2021; Antonio et al. 2019).

The most particular case is represented by the Sardinians: a strong Anatolian Neolithic footprint is visible in the Iron Age samples due to the persistent isolation in previous times and despite the documented contacts with Mycenaeans and Phoenicians (Marcus et al. 2020). Phoenician presence has been dated to as early as the late ninth century BCE (Moscati 2005). Indeed, Eastern Mediterranean genetic signatures have been only found among the post-Nuragic individuals in Phoenician/Punic sites, which could be modelled as direct immigrants or close relatives of the newcomers. Moreover, also the diffusion of Steppe and Iranian-related ancestries, as well as a Northern African component that likely arrived during the Punic (Chartaginean) domination (found in individuals from the Punic Villamar site), has been highlighted in Iron Age samples (Marcus et al. 2020).

As Sardinia, also Sicily was an important Punic trading post, especially on the western coast. Despite the paucity of samples from this area, the presence of Northern African 


\section{Bronze Age}

A

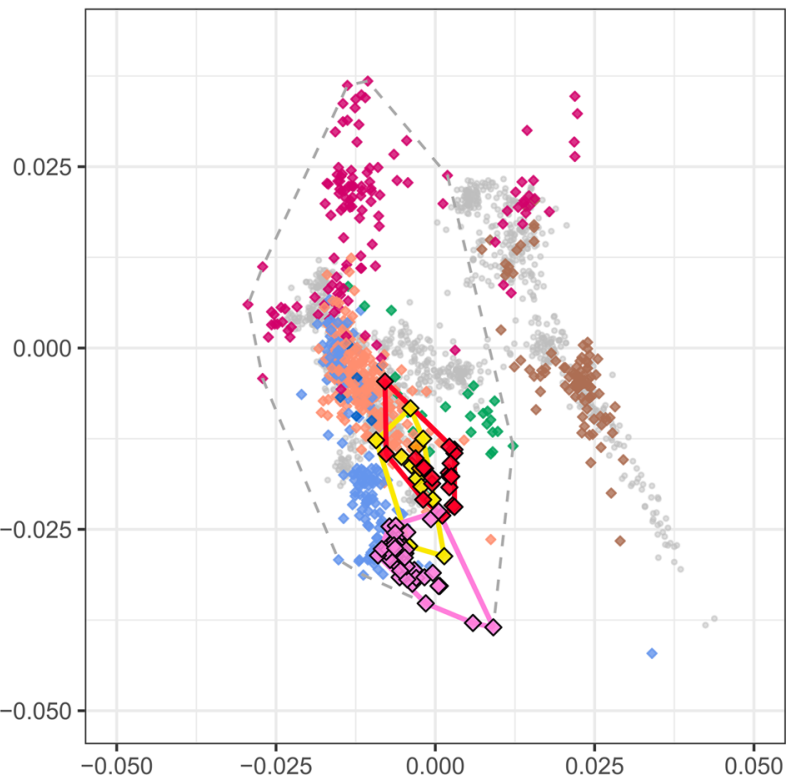

Iron Age

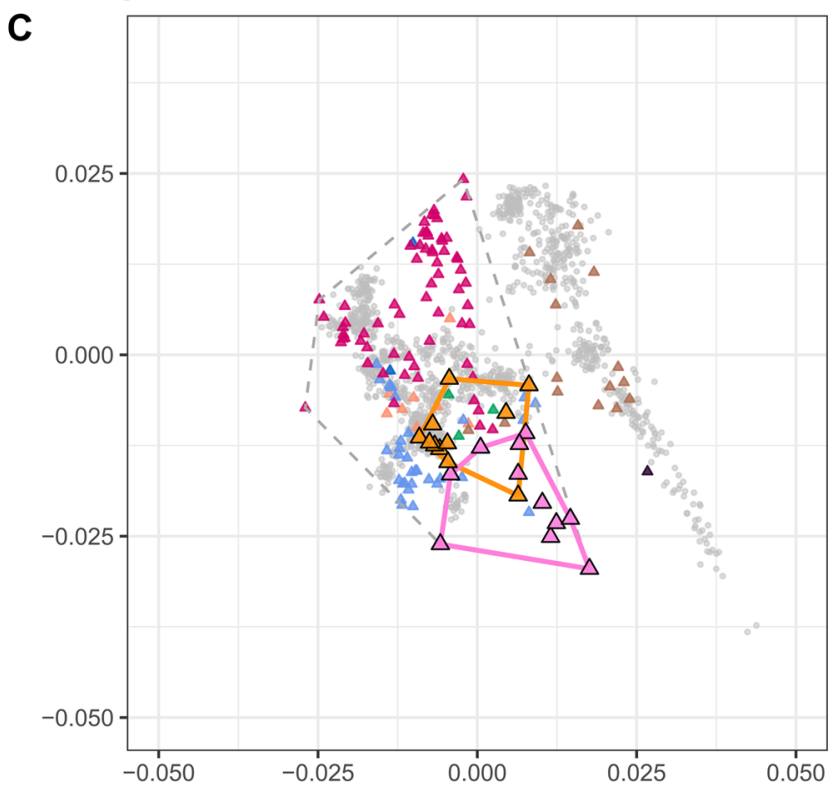

$\diamond$ Bronze Age

$\triangle$ Iron Age

Fig. 3 PCA and outgroup $f_{3}$ multidimensional scaling (MDS) for Bronze and Iron Age samples (A-D, respectively). Samples were divided into four groups according to their chronological and cultural affiliation and projected onto the genetic variation of modern West Eurasians (left column, panels A, C) along with a number of modern reference samples from neighbouring regions. Samples within the
B

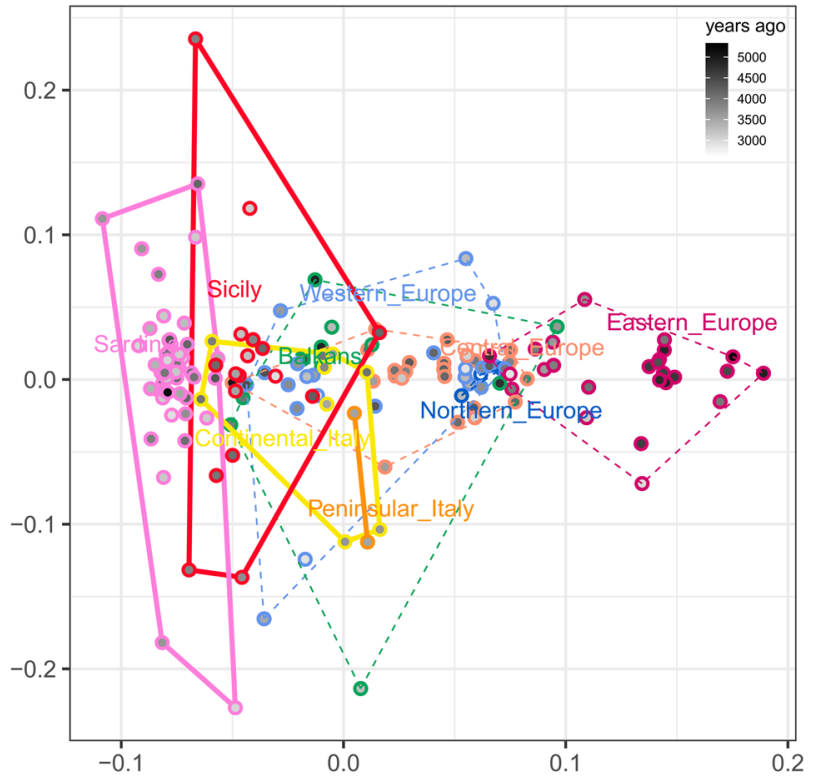

D

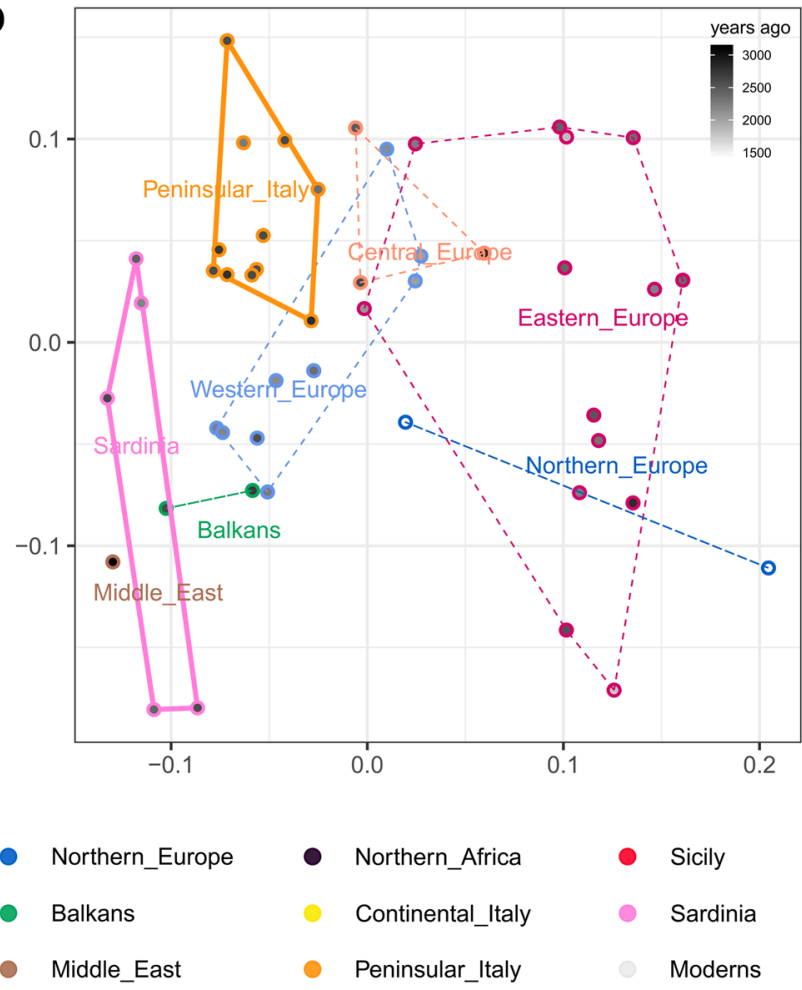

dashed grey polygons were also used to construct a pairwise matrix of outgroup $f_{3}$ distances in the form of $f_{3}$ (Mbuti; X, Y) on which an MDS was performed, hence providing a complementary visualization to the PCA. The chronological dating, based on mean date BP (before present), was used to color-code the samples (right column, panels $\mathbf{B}$, D) 
ancestry on the island could be tentatively reconducted to the Iron Age (or at least Antiquity), because, although absent in previous time layers, it's present in modern Sicilians (Marcus et al. 2020; Fernandes et al. 2020). In addition to the Punics, the other main shapers of the Iron Age Sicilian genetic make-up were the Greeks, who established colonies on the island (and South Italy) starting from the eighth century BCE (Abulafia 2011; Sarno et al. 2017). According to recent findings, the Greek colonization was a more gradual and peaceful process than that described by ancient historians, characterized by greater interaction and close cohabitation between newcomers and local people (Rathmann et al. 2019). This is probably the reason why modern southern Italians display a varying amount of Greek genetic influence (Sarno et al. 2017), which could be described as a "Mediterranean continuum". The Greek-speaking communities in South Italy (Grecani in Calabria and Griko in Apulia) are clearly placed in this continuum and, although there may have been a more recent migration during the Byzantine times (Early Middle Ages), those Greek-speaking communities are believed to have lived in Southern Italy probably since the Magna Graecia times.

If on the one hand Phoenician and Greek Mediterraneanwide trade networks left genetic traces in Sardinians and Southern Italians, on the other hand, it surely had a cultural impact on Etruscans, a population who lived in the Central Italian area named Etruria (between Lazio, Umbria and Tuscany). The Etruscan civilization and, specifically its earliest phase called Villanovan culture, dates back to the ninth century BCE and ended with the slow and gradual Roman assimilation from the sixth century BCE. However, where the Etruscans came from is still uncertain. Both ancient and modern historians have different opinions on the matter and, while some researchers believe in an autochthonous process of formation from the previous Villanovan society, others claim an Anatolian origin (Achilli et al. 2007; Tassi et al. 2013). For instance, a multi-step origin explaining the modern Tuscans genetic composition has been proposed: a proto-Etruscan population, born in a Southeastern region of the Middle East, would have migrated to the Caucasus, then to Lydia and finally arrived in Central Italy at the beginning of Iron Age (Pardo-Seco et al. 2014). However, it is clear that more genetics studies are needed to shed light on this disputed matter.

During the later Iron Age, Etruscans were replaced in their political influence on Central Italy by Rome's rule, a new town that arose in Latium (Central Peninsular Italy) on the banks of the Tiber river. Central Italy and Rome inhabitants of the first millennium BCE exhibited high genetic variability, in particular, they showed a relevant Steppe-related ancestry, an increase in the Iranian-Neolithic component, respect to previous times, and the appearance of the first Northern African signatures on the Peninsula (Antonio et al. 2019). The appearance of such different contributions is the main consequence of the great mobility of people, which increased even more in the later stages of Rome's history during the Republic (509-27 BCE) and the following Empire periods (27 BCE—476 CE; CE: Common Era). During the Iron Age and the first stages of Antiquity, longdistance mobility was promoted by the cosmopolitan nature of the Roman Empire and people from far and wide arrived in Rome, creating a melting pot of languages, cultures, and genes (Abulafia 2011). In particular, many people came from the East (Greece, Syria, Egypt), the richest and most densely inhabited region of the Empire, thus resulting in a genetic shift towards the Eastern Mediterranean areas in individuals from this period (Iron Age) and the subsequent imperial period-classified here as Antiquity (Fig. 3C and Supplementary Fig. 4A). Figure 3C, D clearly points toward the high genetic heterogeneity within Roman and Central Italian individuals, which is a direct consequence of the key role of Rome as the geographical, cultural, and political crossroad of Eastern and Western Mediterranean. These figures also show that the genetic make-up of Italy during the Iron Age was close to the pattern of modern-day populations.

\section{Antiquity and the making of modern Italians}

From the third century CE, the Roman Empire went into a deep crisis due to different causes like strong political instability and military anarchy, population decrease (wars and epidemics), economic stagnation, and invasions from nonRoman populations (Harper 2017). The Empire was also divided into two: the Eastern Roman Empire with the capital Byzantium (today Istanbul, Turkey) and the Western Roman Empire with capital Rome. The latter, poorer in resources and weaker, fell definitively in $476 \mathrm{CE}$ with the deposition of the last Roman emperor by the barbarian commander Odoacer (Mazzarino 1988).

The split of the Empire also had repercussions on the Italian genetic composition. Antonio and colleagues observed a shift from the Eastern Mediterranean to continental Europe in Central Italian samples (Supplementary Fig. 4), which probably resulted from the reduction of the East-West mobility, the demographic drop, and the arrival of people from Central and Eastern Europe. Besides the Romans, the Longobards were another relevant population for the Italian cultural landscape during the Late Antiquity. Samples from the Longobard cemetery of Collegno (Piedmont, Continental Italy) show genetic affinities to Bronze Age people from Central and Eastern Europe (Amorim et al. 2018). However, the genomic background of Northern Italian people preceding the Longobard arrival is still unknown. Thus, it is unclear if they contributed to diffusing the Central European genetic component and what was their real genetic contribution to the Italian inhabitants. Altogether, with the end of 
the Antiquity and the beginning of the Middle Ages (fifth century CE), the Italian genomic scenario reached most of the modern time composition with a high level of individual variability.

The stratified contribution of each time layer to contemporary allele frequencies is evident in Fig. 4, where we magnify the time-dependent allele frequency changes for five variants which have been reported to be genome-wide significant signals of selection among the three main ancestries composing the modern European genetic make-up-huntergatherer, early farmer and Steppe people (Mathieson et al. 2015). The variants in Fig. 4 are associated with lactose metabolism, immune system, skin pigmentation, and eye color (Enattah et al. 2002; Bersaglieri et al. 2004; Soejima and Koda 2007; Sturm et al. 2008; Eiberg et al. 2008; Barreiro et al. 2009; Wong et al. 2010; Teslovich et al. 2010; Divangahi 2013). However, the fact that little has changed after Iron Age and Antiquity does not mean that movements of people across Europe and Italy would have come to an end after that time, rather the incoming populations would have not been so highly diverse as they were before (Günther and Jakobsson 2016).
Homogenizing effects introduced by the pervasive Neolithic and Bronze Age demic diffusions, paired with a steady post-Neolithic population growth that made local populations less and less prone to major genetic turnovers, established a strong genetic continuum all across West Eurasia, making geographic distance the best predictor of similarity and dissimilarity between populations (Pagani et al. 2016). Therefore, contemporary Italians can be seen as the inhabitants of a pier stretched across the Mediterranean Sea, whose genome has been shaped by millennia of landings that made it resonate with the ones of the neighboring populations ashore (Fig. 5).

\section{Materials and methods}

\section{Datasets}

We collected all available ancient human DNA data from the literature, covering a period from Upper Palaeolithic to historical times and mostly coming from Western Eurasia.
Fig. 4 Derived allele frequencies across the four Italian macro-areas for five genetic variants reported to be the strongest significant signals of selection in (Mathieson et al. 2015). The name of the variant (in bold), the allele for which the genetic frequencies are computed (the derived one), the name of the gene, and the associated function are shown above each plot

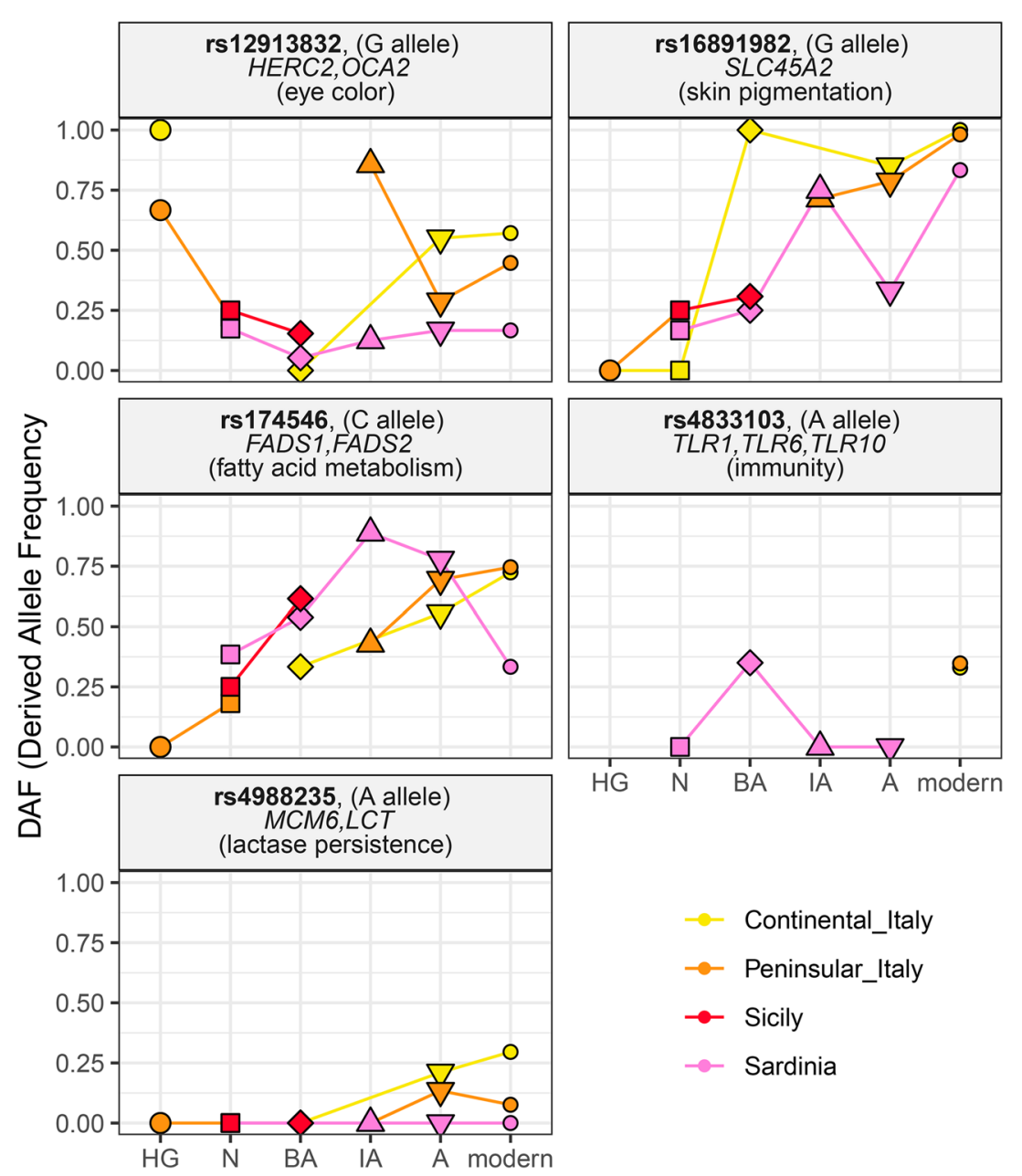


Specifically, we downloaded the $1240 \mathrm{~K}+\mathrm{HO}$ dataset from Dr David Reich laboratory, which comprises present-day and ancient DNA data (version V42.4; https://reich.hms. harvard.edu/allen-ancient-dna-resource-aadr-downloadablegenotypes-present-day-and-ancient-dna-data (Patterson et al. 2012; Gamba et al. 2014; Olalde et al. 2014,2015, 2018, 2019; Skoglund et al. 2014; Lazaridis et al. 2014, 2016, 2017; Allentoft et al. 2015; Fu et al. 2015, 2016; Günther et al. 2015; Jones et al. 2015, 2017; Mathieson et al. 2015, 2018; Cassidy et al. 2016; Martiniano et al. 2016, 2017; Schiffels et al. 2016; Omrak et al. 2016; Hofmanová et al. 2016; Broushaki et al. 2016; K1lınç et al. 2016; GonzálezFortes et al. 2017, 2019; Schuenemann et al. 2017; Unterländer et al. 2017; Saag et al. 2017, 2019; Haber et al. 2017, 2019; Sikora et al. 2017, 2019; Lipson et al. 2017; Damgaard et al. 2018a, b; Fernandes et al. 2018; Krzewińska et al. 2018a, b; Mittnik et al. 2018, 2019; van Loosdrecht et al. 2018; Amorim et al. 2018; Harney et al. 2018; Feldman et al. 2019a, b; Järve et al. 2019; Sánchez-Quinto et al. 2019; Schroeder et al. 2019; Wang et al. 2019; Villalba-Mouco et al. 2019; Biagini et al. 2019; Brace et al. 2019; Jeong et al. 2019; Narasimhan et al. 2019; Antonio et al. 2019). In addition, we added: (1) Bronze Age Southern Levant DNA data (Agranat-Tamir et al. 2020); (2) ancient DNA data from the Balearic Islands, Sicily, and Sardinia (Fernandes et al. 2020); (3) ancient samples from Sardinia spanning the Middle Neolithic to present days (Marcus et al. 2020); (4) the Italian Chalcolithic and Bronze Age samples (Saupe et al. 2021); (5) the genotypes of an Italian hunter-gatherer from the Late Epigravettian site of Riparo Tagliente dated around 17kya (Bortolini et al. 2021).

Finally, we also recovered additional modern-day Italian samples (Raveane et al. 2019).

We converted the dataset to the PLINK format using convertf (for the dataset in EIGENSTRAT format) and the software PLINK 1.9 (Chang et al. 2015) for the vcf file of (Marcus et al. 2020).

We extracted only those modern and ancient samples from the $1240 \mathrm{~K}+\mathrm{HO}$ coming from Western Eurasian countries. More specifically, we selected ancient samples located at latitudes higher than 22 and longitudes between - 15 (Canary Islands) and 60 (the political border between Iran and Afghanistan). We kept the Mbuti individuals from Congo [HGDP, (Patterson et al. 2012)]. We removed items with the string "Ignore" in their "Group.Label" column of the.anno file. Finally, we removed those whose "Assessment" column did not contain the string "PASS". If there were duplicates among ancient individuals, we selected the sample with the highest number of SNPs hit on autosomal targets.

To further refine the backbone of the modern-day European genetic variability, without mixing different genotyping techniques, we selected the modern samples flagged

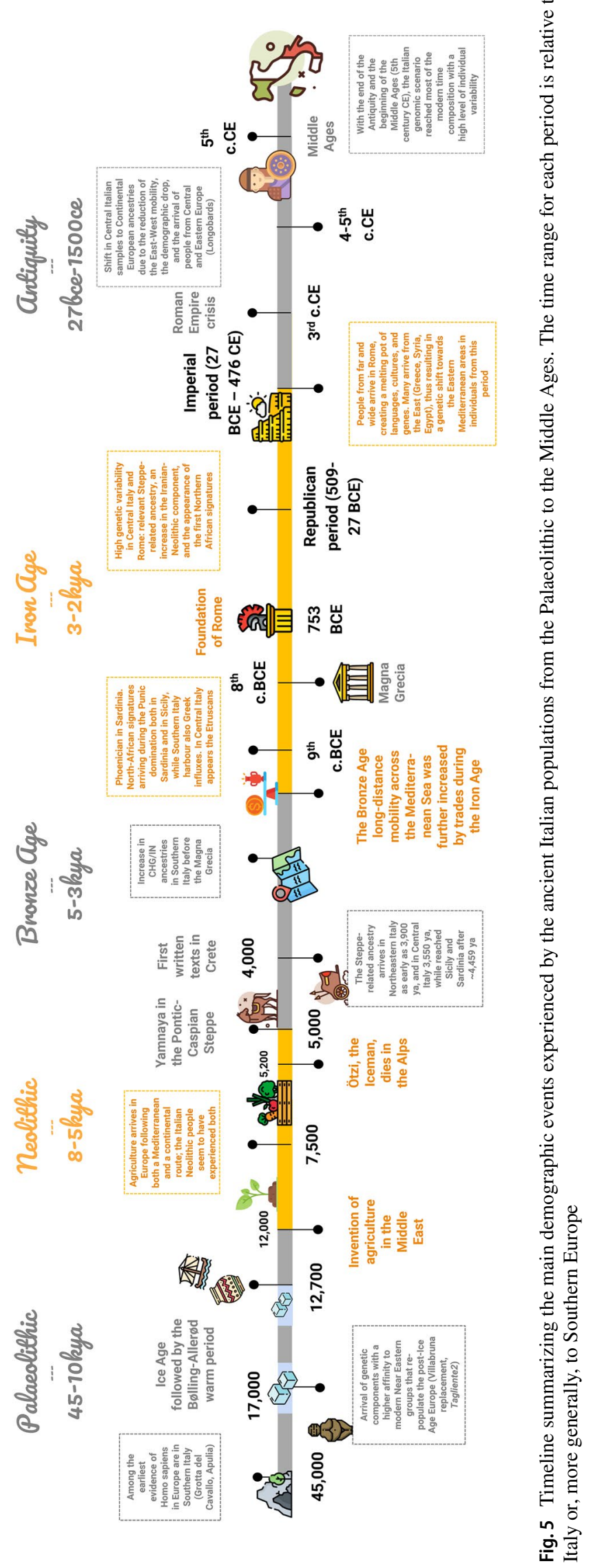


as "PASS (genotyping)" ("Assessment" column) and we removed those coming from Uzbekistan, Kazakhstan, Algeria, Morocco, Tunisia, Libya, as well as some populations from Russia. We excluded SNPs on sexual chromosomes and those monomorphic or with more than 5\% missing data in the modern samples using PLINK.

We extracted the bulk of variants built on modern samples from each dataset and we merged them with PLINK. Finally, we excluded the ancient samples with more than 5000 missing SNPs and we converted the dataset to the EIGENSTRAT format using convertf.

Our final dataset contained 2144 ancient and 1091 modern samples (Supplementary Tables 1,2).

We assigned each sample to a geographic macro-area among "Northern Europe", "Western Europe", "Eastern Europe", "Central Europe", "Continental Italy", "Peninsular Italy", "Sicily", "Sardinia", "Balkans", "Middle East" and "Northern Africa" and to a period among "Huntergatherers", "Neolithic", "Bronze Age", "Iron Age", and "Antiquity" based on the available cultural information (Supplementary Fig. 1A and Supplementary Fig. 2). Given the complete lack of ancient data from Corsica, we do not discuss the genetics of Corsica in this review, even though its geographic proximity to Sardinia and the Italian mainland suggests that many of the demographic changes of Italy would be shared with the island.

We additionally distinguished, among the hunter-gatherers, the Pre- and Post-Villabruna samples using 18kya as a threshold.

\section{Derived allele frequencies variability of selected variants}

We computed the derived allele frequencies for the twelve genetic variants, which have been found under selection among hunter-gatherers, early farmers, and steppe ancestry (Mathieson et al. 2015). Given that some of these SNPs were missing in the Human Origin arrays, we used the $1240 \mathrm{~K}$ dataset (V42.4) which contains the same ancient samples of the $1240 \mathrm{~K}+\mathrm{HO}$ and less modern samples (Supplementary Table 3 contains the list of modern samples of the $1240 \mathrm{~K}$ dataset) (1000 Genomes Project Consortium et al. (1000 Genomes Project Consortium et al. 2015).

\section{Principal components analysis}

We performed principal component analysis using the smartpca function implemented in EIGENSOFT software 8.0.0 (Patterson et al. 2006). Specifically, we projected the ancient samples' genotypes onto the principal components inferred from the modern individuals' genetic variability. We used the options "lsqproject" and "shrinkmode".

\section{$f_{3}$-statistics}

To explore the genetic affinities among ancient samples, we performed a series of Outgroup $f_{3}$ (Patterson et al. 2012; Raghavan et al. 2014) in the form (X, Y; outgroup: Mbuti) using the qp3Pop function (version 650) implemented in ADMIXTOOLS (Patterson et al. 2012). Since the Mbuti population is an outlier with respect to the samples analysed in this review, the resultant $f_{3}$ measures the shared drift between $\mathrm{X}$ and $\mathrm{Y}$ (i.e., the common branch length from the outgroup), in a way that the higher is the $f_{3}$, the closer is the relatedness between the two populations.

We grouped the non-Italian ancient samples into higher cultural labels, which are shown in the column "Higher. Label" of Supplementary Table 1 and we performed the Outgroup $f_{3}$, after removing samples flagged as outliers or with family relationships with other individuals (Supplementary Table 4).

Finally, we computed the distance matrices from the Outgroup $f_{3}$ results by subtracting the $f_{3}$ values from 1 and we performed a classical (metric) multi-dimensional scaling (MDS) with default options from such distance matrices using the function cmdscale in the stats package of $\mathrm{R}$ [version 4.0.4 (R Core Team 2021)]. When necessary, we iteratively removed the outliers and recomputed the MDS.

Supplementary Information The online version contains supplementary material available at https://doi.org/10.1007/s00439-021-02328-6.

Acknowledgements This work was supported by Unipd PRID 2019 (S. A., L. P.). We would like to thank the authors of Flaticon (https://www. flaticon.com) that created the icons used in Fig. 5 (Freepik, photo3ideastudio, Darius Dan, Flat Icons, Smashicons).

Funding Open access funding provided by Università degli Studi di Padova within the CRUI-CARE Agreement.

Data availability All data used in this work are publicly available.

\section{Declarations}

Conflict of interest The authors declare that they have no competing interests.

Open Access This article is licensed under a Creative Commons Attribution 4.0 International License, which permits use, sharing, adaptation, distribution and reproduction in any medium or format, as long as you give appropriate credit to the original author(s) and the source, provide a link to the Creative Commons licence, and indicate if changes were made. The images or other third party material in this article are included in the article's Creative Commons licence, unless indicated otherwise in a credit line to the material. If material is not included in the article's Creative Commons licence and your intended use is not permitted by statutory regulation or exceeds the permitted use, you will need to obtain permission directly from the copyright holder. To view a copy of this licence, visit http://creativecommons.org/licenses/by/4.0/. 


\section{References}

1000 Genomes Project Consortium, Auton A, Brooks LD et al (2015) A global reference for human genetic variation. Nature 526:68-74

Abulafia D (2011) The great sea: a human history of the Mediterranean. Oxford University Press

Achilli A, Olivieri A, Pala M et al (2007) Mitochondrial DNA variation of modern Tuscans supports the near eastern origin of Etruscans. Am J Hum Genet 80:759-768

Agranat-Tamir L, Waldman S, Martin MAS et al (2020) The genomic history of the bronze age southern levant. Cell 181:1146-1157. e11

Allentoft ME, Sikora M, Sjögren K-G et al (2015) Population genomics of Bronze Age Eurasia. Nature 522:167-172

Ammerman AJ, Cavalli-Sforza LL (1984) The neolithic transition and the genetics of populations in Europe. Princeton University Press

Amorim CEG, Vai S, Posth C et al (2018) Understanding 6th-century barbarian social organization and migration through paleogenomics. Nat Commun 9:3547

Anagnostou P, Dominici V, Battaggia C et al (2017) Overcoming the dichotomy between open and isolated populations using genomic data from a large European dataset. Sci Rep 7:41614

Aneli S, Saupe T, Montinaro F et al (2021) The genetic origin of Daunians and the Pan-Mediterranean southern Italian Iron Age context. https://doi.org/10.1101/2021.07.30.454498

Antonio ML, Gao Z, Moots HM et al (2019) Ancient Rome: a genetic crossroads of Europe and the Mediterranean. Science 366:708-714

Artioli G, Angelini I, Kaufmann G et al (2017) Long-distance connections in the Copper Age: new evidence from the Alpine Iceman's copper axe. PLoS ONE 12:0179263

Barreiro LB, Ben-Ali M, Quach H et al (2009) Evolutionary dynamics of human Toll-like receptors and their different contributions to host defense. PLoS Genet 5:1000562

Benazzi S, Douka K, Fornai C et al (2011) Early dispersal of modern humans in Europe and implications for Neanderthal behaviour. Nature 479:525-528

Benazzi S, Bailey SE, Peresani M et al (2014) Middle Paleolithic and Uluzzian human remains from Fumane Cave, Italy. J Hum Evol 70:61-68

Bersaglieri T, Sabeti PC, Patterson N et al (2004) Genetic signatures of strong recent positive selection at the lactase gene. Am J Hum Genet 74:1111-1120

Biagini SA, Solé-Morata N, Matisoo-Smith E et al (2019) People from Ibiza: an unexpected isolate in the Western Mediterranean. Eur J Hum Genet 27:941-951

Bietti Sestieri AM (2010) L'Italia nell'età del bronzo e del ferro. Dalle palafitte a Romolo (2200-700 a. C.). Carocci editore

Boattini A, Martinez-Cruz B, Sarno S et al (2013) Uniparental markers in Italy reveal a sex-biased genetic structure and different historical strata. PLoS ONE 8:65441

Bortolini E, Pagani L, Oxilia G et al (2021) Early Alpine occupation backdates westward human migration in Late Glacial Europe. Curr Biol. https://doi.org/10.1016/j.cub.2021.03.078

Brace S, Diekmann Y, Booth TJ et al (2019) Author correction: ancient genomes indicate population replacement in Early Neolithic Britain. Nat Ecol Evol 3:986-987

Broodbank C (2006) The origins and early development of mediterranean maritime activity. J Mediterr Archaeol 19:2

Broushaki F, Thomas MG, Link V et al (2016) Early Neolithic genomes from the eastern Fertile Crescent. Science 353:499-503

Bruner E, Manzi G (2006) Saccopastore 1: the earliest Neanderthal? A new look at an old cranium. In: Neanderthals revisited: new approaches and perspectives. Springer, Netherlands, Dordrecht, pp 23-36

Capocasa M, Anagnostou P, Bachis V et al (2014) Linguistic, geographic and genetic isolation: a collaborative study of Italian populations. J Anthropol Sci 92:201-231

Cassidy LM, Martiniano R, Murphy EM et al (2016) Neolithic and Bronze Age migration to Ireland and establishment of the insular Atlantic genome. Proc Natl Acad Sci U S A 113:368-373

Catalano G, Lo Vetro D, Fabbri PF et al (2020) Late Upper Palaeolithic hunter-gatherers in the Central Mediterranean: new archaeological and genetic data from the Late Epigravettian burial Oriente C (Favignana, Sicily). Quat Int 537:24-32

Cavalli-Sforza LL (2001) Genes, peoples and languages. Penguin Books

Chang CC, Chow CC, Tellier LC et al (2015) Second-generation PLINK: rising to the challenge of larger and richer datasets. Gigascience 4:7

Cunliffe BW (2008) Europe between the Oceans, 9000 BC to AD 1000. Yale University Press, New Haven

de Barros Damgaard P, Martiniano R (2018a) The first horse herders and the impact of early Bronze Age steppe expansions into Asia. Science 360:eaar7711

de Barros Damgaard P, Marchi N, Rasmussen S et al (2018b) 137 Ancient human genomes from across the Eurasian steppes. Nature 557:369-374

Divangahi M (2013) The new paradigm of immunity to tuberculosis. Springer New York

Eiberg H, Troelsen J, Nielsen M et al (2008) Blue eye color in humans may be caused by a perfectly associated founder mutation in a regulatory element located within the HERC2 gene inhibiting OCA2 expression. Hum Genet 123:177-187

Enattah NS, Sahi T, Savilahti E et al (2002) Identification of a variant associated with adult-type hypolactasia. Nat Genet 30:233-237

Feldman M, Fernández-Domínguez E, Reynolds et al (2019a) Late Pleistocene human genome suggests a local origin for the first farmers of central Anatolia. Nat Commun 10:1218

Feldman M, Master DM, Bianco RA et al (2019b) Ancient DNA sheds light on the genetic origins of early Iron Age Philistines. Sci Adv 5:eaax0061

Fernandes DM, Strapagiel D, Borówka P et al (2018) A genomic Neolithic time transect of hunter-farmer admixture in central Poland. Sci Rep 8:14879

Fernandes DM, Mittnik A, Olalde I et al (2020) The spread of steppe and Iranian-related ancestry in the islands of the western Mediterranean. Nat Ecol Evol 4:334-345

Fiorito G, Di Gaetano C, Guarrera S et al (2016) The Italian genome reflects the history of Europe and the Mediterranean basin. Eur J Hum Genet 24:1056-1062

Fowler C, Harding J, Hofmann D (2015) The Oxford handbook of Neolithic Europe. Oxford University Press

Fu Q, Hajdinjak M, Moldovan OT et al (2015) An early modern human from Romania with a recent Neanderthal ancestor. Nature 524:216-219

Fu Q, Posth C, Hajdinjak M et al (2016) The genetic history of Ice Age Europe. Nature 534:200-205

Gamba C, Jones ER, Teasdale MD et al (2014) Genome flux and stasis in a five millennium transect of European prehistory. Nat Commun 5:5257

González-Fortes G, Jones ER, Lightfoot E et al (2017) Paleogenomic evidence for multi-generational mixing between Neolithic farmers and Mesolithic hunter-gatherers in the lower Danube basin. Curr Biol 27:1801-1810.e10

González-Fortes G, Tassi F, Trucchi E et al (2019) A western route of prehistoric human migration from Africa into the Iberian Peninsula. Proc Royal Soc B: Biol Sci 286:20182288 
Günther T, Jakobsson M (2016) Genes mirror migrations and cultures in prehistoric Europe-a population genomic perspective. Curr Opin Genet Dev 41:115-123

Günther T, Valdiosera C, Malmström H et al (2015) Ancient genomes link early farmers from Atapuerca in Spain to modern-day Basques. Proc Natl Acad Sci U S A 112:11917-11922

Haak W, Lazaridis I, Patterson N et al (2015) Massive migration from the steppe was a source for Indo-European languages in Europe. Nature 522:207-211

Haber M, Doumet-Serhal C, Scheib C et al (2017) Continuity and admixture in the last five millennia of levantine history from ancient canaanite and present-day Lebanese genome sequences. Am J Hum Genet 101:274-282

Haber M, Doumet-Serhal C, Scheib CL et al (2019) A transient pulse of genetic admixture from the crusaders in the near east identified from ancient genome sequences. Am J Human Genet 104:977-984

Harding A, Fokkens H (2013) The Oxford handbook of the European bronze age. Oxford University Press

Harney É, May H, Shalem D et al (2018) Publisher correction: ancient DNA from Chalcolithic Israel reveals the role of population mixture in cultural transformation. Nat Commun 9:3913

Harper K (2017) The fate of Rome: climate, disease, and the end of an Empire. Princeton University Press

Hofmanová Z, Kreutzer S, Hellenthal G et al (2016) Early farmers from across Europe directly descended from Neolithic Aegeans. Proc Natl Acad Sci U S A 113:6886-6891

Järve M, Saag L, Scheib CL et al (2019) Shifts in the genetic landscape of the western Eurasian steppe associated with the beginning and end of the Scythian dominance. Curr Biol 29:24302441.e10

Jeong C, Balanovsky O, Lukianova E et al (2019) The genetic history of admixture across inner Eurasia. Nat Ecol Evol 3:966-976

Jones ER, Gonzalez-Fortes G, Connell S et al (2015) Upper Palaeolithic genomes reveal deep roots of modern Eurasians. Nat Commun 6:8912

Jones ER, Zarina G, Moiseyev V et al (2017) The neolithic transition in the baltic was not driven by admixture with early European Farmers. Curr Biol 27:576-582

Keller A, Graefen A, Ball M et al (2012) New insights into the Tyrolean Iceman's origin and phenotype as inferred by whole-genome sequencing. Nat Commun 3:698

Kılınç GM, Omrak A, Özer F et al (2016) The demographic development of the first farmers in Anatolia. Curr Biol 26:2659-2666

Krzewińska M, Kılınç GM, Juras A et al (2018a) Ancient genomes suggest the eastern Pontic-Caspian steppe as the source of western Iron Age nomads. Sci Adv 4:eaat4457

Krzewińska M, Kjellström A, Günther T et al (2018b) Genomic and strontium isotope variation reveal immigration patterns in a viking age town. Curr Biol 28:2730-2738.e10

Lari M, Di Vincenzo F, Borsato A et al (2015) The Neanderthal in the karst: first dating, morphometric, and paleogenetic data on the fossil skeleton from Altamura (Italy). J Hum Evol 82:88-94

Lazaridis I, Patterson N, Mittnik A et al (2014) Ancient human genomes suggest three ancestral populations for present-day Europeans. Nature 513:409-413

Lazaridis I, Nadel D, Rollefson G et al (2016) Genomic insights into the origin of farming in the ancient Near East. Nature 536:419-424

Lazaridis I, Mittnik A, Patterson N et al (2017) Genetic origins of the Minoans and Mycenaeans. Nature 548:214-218

Lipson M, Szécsényi-Nagy A, Mallick S et al (2017) Parallel palaeogenomic transects reveal complex genetic history of early European farmers. Nature 551:368-372

Mallory JP, Adams DQ, Adams DQ (1997) Encyclopedia of IndoEuropean Culture. Taylor \& Francis
Manco J (2016) Ancestral journeys: the peopling of Europe from the first venturers to the vikings (revised and updated edition). Thames \& Hudson

Manzi G, Mallegni F, Ascenzi A (2001) A cranium for the earliest Europeans: phylogenetic position of the hominid from Ceprano, Italy. Proc Natl Acad Sci U S A 98:10011-10016

Marcus JH, Posth C, Ringbauer H et al (2020) Genetic history from the Middle Neolithic to present on the Mediterranean island of Sardinia. Nat Commun 11:939

Martini F (2019) Archeologia del Paleolitico. Storia e culture dei popoli cacciatori-raccoglitori. Carocci editore

Martiniano R, Caffell A, Holst M et al (2016) Genomic signals of migration and continuity in Britain before the Anglo-Saxons. Nat Commun 7:10326

Martiniano R, Cassidy LM, Ó’Maoldúin R et al (2017) The population genomics of archaeological transition in west Iberia: Investigation of ancient substructure using imputation and haplotype-based methods. PLoS Genet 13:1006852

Mathieson I, Lazaridis I, Rohland N et al (2015) Genome-wide patterns of selection in 230 ancient Eurasians. Nature 528:499-503

Mathieson I, Alpaslan-Roodenberg S, Posth C et al (2018) The genomic history of southeastern Europe. Nature 555:197-203

Mazzarino S (1988) La fine del mondo antico. Rizzoli, Milano

Mittnik A, Wang C-C, Pfrengle S et al (2018) The genetic prehistory of the Baltic Sea region. Nat Commun 9:442

Mittnik A, Massy K, Knipper C et al (2019) Kinship-based social inequality in Bronze Age Europe. Science 366:731-734

Moscati S (2005) Fenici e cartaginesi in Sardegna. Ilisso, Nuoro

Mussi M (2006) Earliest Italy: an overview of the Italian Paleolithic and Mesolithic. Springer

Narasimhan VM, Patterson N, Moorjani P et al (2019) The formation of human populations in South and Central Asia. Science. https://doi.org/10.1126/science.aat7487

Olalde I, Allentoft ME, Sánchez-Quinto F et al (2014) Derived immune and ancestral pigmentation alleles in a 7,000-yearold Mesolithic European. Nature 507:225-228

Olalde I, Schroeder H, Sandoval-Velasco M et al (2015) A common genetic origin for early farmers from Mediterranean cardial and central European LBK cultures. Mol Biol Evol 32:3132-3142

Olalde I, Brace S, Allentoft ME et al (2018) The Beaker phenomenon and the genomic transformation of northwest Europe. Nature 555:190-196

Olalde I, Mallick S, Patterson N et al (2019) The genomic history of the Iberian Peninsula over the past 8000 years. Science 363:1230-1234

Omrak A, Günther T, Valdiosera C et al (2016) Genomic evidence establishes Anatolia as the source of the European Neolithic gene pool. Curr Biol 26:270-275

Pagani L, Lawson DJ, Jagoda E et al (2016) Genomic analyses inform on migration events during the peopling of Eurasia. Nature 538:238-242

Pais E (1988) Storia dell'Italia antica. Melita, La Spezia

Pankratov V, Montinaro F, Kushniarevich A et al (2020) Differences in local population history at the finest level: the case of the Estonian population. Eur J Hum Genet 28:1580-1591

Pardo-Seco J, Gómez-Carballa A, Amigo J et al (2014) A genomewide study of modern-day Tuscans: revisiting Herodotus's theory on the origin of the Etruscans. PLoS ONE 9:105920

Patterson N, Price AL, Reich D (2006) Population structure and eigenanalysis. PLoS Genet 2:190

Patterson N, Moorjani P, Luo Y et al (2012) Ancient admixture in human history. Genetics 192:1065-1093

Peresani M, Margaritora D, Breda M et al (2020) Hunter-gatherers across the great Adriatic-Po region during the Last Glacial 
Maximum: environmental and cultural dynamics. Quat Int. https://doi.org/10.1016/j.quaint.2020.10.007

Peretto C (2006) The first peopling of southern Europe: the Italian case. CR Palevol 5:283-290

Peroni R (1989) Protostoria dell'Italia continentale: la penisola italiana nelle età del bronzo e delferro. Biblioteca Di Storia Patria, Roma

Pessina A, Tiné V (2008) Archeologia del neolitico: l'Italia tra VI e IV millennio a.C. Carocci editore

Posth C, Renaud G, Mittnik A et al (2016) Pleistocene mitochondrial genomes suggest a single major dispersal of non-Africans and a late glacial population turnover in Europe. Curr Biol 26:557-561

R Core Team (2021) R: a language and environment for statistical computing. R Foundation for Statistical Computing, Vienna, Austria

Raghavan M, Skoglund P, Graf KE et al (2014) Upper Palaeolithic Siberian genome reveals dual ancestry of Native Americans. Nature 505:87-91

Rathmann H, Kyle B, Nikita E et al (2019) Population history of southern Italy during Greek colonization inferred from dental remains. Am J Phys Anthropol 170:519-534

Raveane A, Aneli S, Montinaro F et al (2019) Population structure of modern-day Italians reveals patterns of ancient and archaic ancestries in Southern Europe. Sci Adv 5:eaaw492

Rivollat M, Jeong C, Schiffels S et al (2020) Ancient genome-wide DNA from France highlights the complexity of interactions between Mesolithic hunter-gatherers and Neolithic farmers. Sci Adv 6:eaaz5344

Rohrlach AB, Papac L, Childebayeva A et al (2021) Using Y-chromosome capture enrichment to resolve haplogroup $\mathrm{H} 2$ shows new evidence for a two-Path Neolithic expansion to Western Europe. Sci Rep 11:15005

Saag L, Varul L, Scheib CL et al (2017) Extensive farming in Estonia started through a sex-biased migration from the steppe. Curr Biol 27:2185-2193.e6

Saag L, Laneman M, Varul L et al (2019) The arrival of Siberian ancestry connecting the eastern Baltic to Uralic speakers further East. Curr Biol 29:1701-1711.e16

Sabatini S, Lo Schiavo F (2020) Late bronze age metal exploitation and trade: Sardinia and Cyprus. Mater Manuf Process 35:1501-1518

Sánchez-Quinto F, Malmström H, Fraser M et al (2019) Megalithic tombs in western and northern Neolithic Europe were linked to a kindred society. Proc Natl Acad Sci 116:9469-9474

Sarno S, Boattini A, Pagani L et al (2017) Ancient and recent admixture layers in Sicily and Southern Italy trace multiple migration routes along the Mediterranean. Sci Rep 7:1984

Saupe T, Montinaro F, Scaggion C et al (2021) Ancient genomes reveal structural shifts after the arrival of Steppe-related ancestry in the Italian Peninsula. Curr Biol. https://doi.org/10.1016/j.cub. 2021.04.022

Sazzini M, Gnecchi Ruscone GA, Giuliani C et al (2016) Complex interplay between neutral and adaptive evolution shaped differential genomic background and disease susceptibility along the Italian peninsula. Sci Rep 6:32513

Sazzini M, Abondio P, Sarno S et al (2020) Genomic history of the Italian population recapitulates key evolutionary dynamics of both Continental and Southern Europeans. BMC Biol 18:51

Schiffels S, Haak W, Paajanen P et al (2016) Iron Age and Anglo-Saxon genomes from East England reveal British migration history. Nat Commun 7:10408
Schroeder H, Margaryan A, Szmyt M et al (2019) Unraveling ancestry, kinship, and violence in a Late Neolithic mass grave. Proc Natl Acad Sci 116:10705-10710

Schuenemann VJ, Peltzer A, Welte B et al (2017) Ancient Egyptian mummy genomes suggest an increase of Sub-Saharan African ancestry in post-Roman periods. Nat Commun 8:15694

Shennan S, Downey SS, Timpson A et al (2013) Regional population collapse followed initial agriculture booms in mid-Holocene Europe. Nat Commun 4:2486

Sikora M, Seguin-Orlando A, Sousa VC et al (2017) Ancient genomes show social and reproductive behavior of early Upper Paleolithic foragers. Science 358:659-662

Sikora M, Pitulko VV, Sousa VC et al (2019) The population history of northeastern Siberia since the Pleistocene. Nature 570:182-188

Skoglund P, Malmström H, Raghavan M et al (2012) Origins and genetic legacy of Neolithic farmers and hunter-gatherers in Europe. Science 336:466-469

Skoglund P, Malmström H, Omrak A et al (2014) Genomic diversity and admixture differs for Stone-Age Scandinavian foragers and farmers. Science 344:747-750

Soejima M, Koda Y (2007) Population differences of two coding SNPs in pigmentation-related genes SLC24A5 and SLC45A2. Int J Legal Med 121:36-39

Stewart JR, Stringer CB (2012) Human evolution out of Africa: the role of refugia and climate change. Science 335:1317-1321

Sturm RA, Duffy DL, Zhao ZZ et al (2008) A single SNP in an evolutionary conserved region within intron 86 of the HERC2 gene determines human blue-brown eye color. Am J Hum Genet $82: 424-431$

Tassi F, Ghirotto S, Caramelli D, Barbujani G (2013) Genetic evidence does not support an etruscan origin in Anatolia. Am J Phys Anthropol 152:11-18

Teslovich TM, Musunuru K, Smith AV et al (2010) Biological, clinical and population relevance of 95 loci for blood lipids. Nature 466:707-713

Ugas G (2006) L'alba dei nuraghi. Fabula, Cagliari

Unterländer M, Palstra F, Lazaridis I et al (2017) Ancestry and demography and descendants of Iron Age nomads of the Eurasian Steppe. Nat Commun 8:14615

van de Loosdrecht M, Bouzouggar A, Humphrey L et al (2018) Pleistocene North African genomes link Near Eastern and sub-Saharan African human populations. Science 360:548-552

Villalba-Mouco V, van de Loosdrecht MS, Posth C et al (2019) Survival of late Pleistocene hunter-gatherer ancestry in the Iberian Peninsula. Curr Biol 29:1169-1177.e7

Wang C-C, Reinhold S, Kalmykov A et al (2019) Ancient human genome-wide data from a 3000-year interval in the Caucasus corresponds with eco-geographic regions. Nat Commun 10:590

Wong SH, Gochhait S, Malhotra D et al (2010) Leprosy and the adaptation of human toll-like receptor 1. PLoS Pathog 6:1000979

Publisher's Note Springer Nature remains neutral with regard to jurisdictional claims in published maps and institutional affiliations. 